\title{
Detection of Member Overall Buckling in Civil Space Grid Structures Based on Deviation in Normal Strain along the Member
}

\author{
Guirong Yan ${ }^{1}$; Chen Fang ${ }^{2}$; Ruoqiang Feng ${ }^{3}$; Xugang Hua ${ }^{4}$; and Yi Zhao ${ }^{5}$
}

${ }^{1}$ Department of Civil, Architectural and Environmental Engineering, Missouri University of Science and Technology, Rolla, MO 65409 (corresponding author). Email: yang@mst.edu

${ }^{2}$ Department of Civil Engineering, University of Texas at El Paso, El Paso, TX 79968. Email: cfang@miners.utep.edu

3 The Key Laboratory of Concrete and Prestressed Concrete Structures of Ministry of Education, Southeast University, Nanjing, Jiangsu, China 210096. Email: hitfeng@163.com

${ }^{4}$ Department of Architecture and Civil Engineering, Hunan University, Changsha, Hunan, China 410082. Email: cexghua@hotmail.com

${ }^{5}$ Department of Civil, Architectural and Environmental Engineering, Missouri University of Science and Technology, Rolla, MO 65409. Email: yzvxd@mst.edu

Abstract: A number of structural collapses are initiated from losing stability locally. The monitoring and detection of instability is rarely studied in both research communities of structural health monitoring and structural stability. In order to capture member buckling at an early stage to prevent a local instability from propagating into an overall structural failure, in this study, an approach to detect one type of instability (member overall buckling) is proposed for civil large-scale space grid structures. The foundation of this approach lies in: once a member buckles, a large bending stress due to buckling is developed and dominates the total normal stress of the member. Since the bending stress varies along a member, the total normal stress varies along the member, so does the total normal strain on the surface of the member. Therefore, by identifying the deviation in normal strain at two different cross sections of a member, overall buckling of the member can be detected. This study will justify that strain gauges can pick up all the bending stress induced by buckling as long as they are deployed before buckling. Numerical simulations have been conducted on large-scale space grid structures with different types of connections between members and loading situations. The obtained results have shown that once a member buckles, the strains measured at two different cross sections on the member deviate from each other significantly, verifying the efficacy of the proposed approach.

Keyword: Buckling Detection; Instability Detection; Space Grid Structures; Space Structures; Normal Strain

\section{Introduction}

In the community of structural health monitoring (SHM) and damage detection, the majority of previous research efforts has been focused on the detection of stiffness reduction of structural members caused by various reasons, such as corrosion, material aging, fatigue or extreme loading. However, the detection of the loss of stability (e.g., buckling), which can easily result in an overall structural failure, has been lacking. On the other hand, the structural stability community has also conducted extensive research. However, they normally focus on how to determine the critical buckling load, and ignore the detection of instability. This research is to bridge the gap between SHM and structural stability research by proposing an approach to detect one type of instability (member overall buckling) for space grid structures at an early stage, 
which will prevent a local buckling from propagating into an overall structural failure. Space grid structures are usually built to cover venues where hundreds or even thousands of people assemble, and thus detection of buckling of this type of structure to ensure their safety and integrity is significant to improve the safety of the general public.

Indeed, instability is one type of strength limit state in design specifications. However, a number of unknown or unmeasurable adverse factors may lead structures to fail by instability much earlier than expected. For example, in some space grid structures, the ends of the member may be tapered to facilitate a particular type of joint. This tapering may reduce the flexural stiffness of the member and reduce the buckling strength of the member. Also, the use of tee and angle sections may cause the member to be loaded eccentrically, which decreases the buckling strength of the member. Furthermore, some geometric imperfections (initial out-of-straightness, misalignment or lack-of-fit) and material imperfection (particularly with welded joints) that are usually unmeasurable may result in a premature structural failure at loads much lower than those predicted by theory [1]. Therefore, there is a strong need to identify local instability timely to avoid a structural failure.

Instability can be classified into static instability and dynamic instability. Static instability can occur under agglomerated snow, ice and other unexpected local or global loads; and dynamic instability can occur under non-conservative loads, such as wind loads or earthquake loads. Depending on the type of structure, static instability for civil space structures can be further classified into individual member buckling and nodal snap-through instability. This study will be focused on individual member buckling. To be specific, it is to propose an approach to detect member overall buckling of space grid structures.

Buckling has often been connected with "a sudden failure" intuitively, leading to the assumption that it is not important to detect buckling, since people have no time to respond even though buckling can be detected in advance. Although a sudden failure happened to an independent single member under axial compressive loading in the laboratory, buckling of a single member in a space grid structure does not mean an immediate collapse of the overall structure due to the fact that there are several members connected at each joint and the structure is redundant. Instead, buckling of a single member can cause the member internal forces to redistribute, and the external loads can then further increase until another member buckles, and so forth until many members buckle, leading the overall structure to collapse $[2,3,4]$. Therefore, it is significant to develop an approach to identify buckling in individual members in space grid structures in a timely manner, which will guide the maintenance crew to take measures to prevent individual member buckling from progressing into a collapse of the overall structure.

Although a great number of damage detection approaches have been developed in the field of structural health monitoring, they may not be able to detect buckling. The reason is as follows: member buckling is essentially induced by the softening of local structural stiffness, which is caused by large deformation and/or yielding of local materials, depending on the type of buckling. That is to say, geometric nonlinearity and/or material nonlinearity are introduced when buckling occurs. Therefore, the principle of superimposition of effects does not work here, and thus previous damage detection approaches, which are mostly based on modal analysis, are not applicable here.

Very rarely, research on detecting buckling was reported in the literature. For example, one approach is based on the change in natural frequency. It was proposed based on the following observation: during the buckling testing of an independent single member, as the static compressive load increased, structural natural frequencies gradually decreased; when the load 
reached the critical buckling load of the member, the first natural frequency of the member decreased to zero[5,6]. Therefore, by tracking the change in natural frequencies identified from measured acceleration responses, buckling can be identified. Unfortunately, for a space grid structure, which is usually indeterminate and redundant, buckling of one member does not usually cause the natural frequencies of the overall structure to change appreciably, not to even mention a decrease of the natural frequency to zero. Qu et al. [7] proposed a two-step approach to detect the buckling of major vertical members in power transmission towers. The first step was to locate the regions of buckling using wavelet packet energy curvature; and the second step was to further locate buckling into exact members using modal strain energy and interval estimation. However, since modal parameters are used here, this approach may be only applicable to cases where the linearity is still valid, which is unfortunately not true for most cases where buckling occurs. Ravet et al. [8] used a distributed Brillouin sensor system to monitor buckling of a steel pipe and column. To initiate buckling, locally thinning the inner wall was applied to two specimens (steel pipe and column). The member was found buckled if the shortening on the whole specimen and elongation in the neighborhood of the thinned wall were detected. By using the broadening factor of the Brillouin spectrum width, the distributed Brillouin sensor system predicted both the magnitude and location of buckling of pipes [9]. This approach is only applied to detect member local buckling. Most recently, Feng et al. detected the lateral buckling of subsea pipelines by mounting the Brillouin optical time domain analysis (BOTDA) distributed sensors on the outer surface of the pipeline. The extracted bending-induced strain is used to indicate the occurrence and evolution of lateral buckling. These newly developed BOTDA distributed sensors has been validated by a series of numerical simulations and experimental testing [10,11,12]. Ryu et al. [13] developed an FBG strain sensing system based on a wavelength-swept fiber laser (WSFL) to monitor the buckling behavior of a composite wing box. Similarly, Park et al. [14] proposed to detect buckling in delaminated composites by embedding one type of fiber optic sensors (extrinsic Fabry-Perot interferometer) into composites. However, these two approaches require that the FBG sensors be embedded into structural components, which may not be realistic for existing structures.

To bridge the research gap between SHM and structural stability, the objective of this research is to propose an approach to detect overall buckling of individual members in space grid structures automatically, instead of using visual inspection. In practice, for civil space grid structures, they are mostly built as roofs, which are normally located at a very high elevation. Therefore, it is impossible to observe buckling from the ground, even though buckling may produce a significant deformation; In addition, if visual inspection is implemented, it will be very expensive, in terms of equipment to reach the space grid structure (roof), labor and time, and it will affect the normal operation of the building. Therefore, the purpose of this study is to detect buckling automatically using sensors. This way, once member buckling is detected, the obtained detection results will be sent to the maintenance/repair crew immediately to take measures timely before the buckling of the first member leads to the buckling of more members and then the collapse of the overall structure, to avoid catastrophic failures. The buckling type to be detected in this study is flexural buckling. The proposed detection approach in this study is based on the fact that buckling introduces a large bending stress, which leads to the total normal stress to vary significantly along the member. The variation in stress can be reflected in the deviation in strain along the member picked up by strain gauges. Herein the postbuckling behavior of members is taken advantage of. 
Considering that nonlinear buckling analyses will be implemented in this study, the following literature was reviewed. To predict the ultimate strength and the related failure mode of thin reinforced concrete shells, a numerical model based on an elasto-plastic-fracturing formulation is developed. In particular, the buckling behavior of two-directional structures was successfully simulated numerically [15]. Through a combined experimental and analytical study, Foraboschi found that geometric non-linear behavior of glass members cannot be described using the same model as steel structures. He proposed a new analytical model to describe the behavior of glass members subjected to combined compression and bending [16]. In addition, Foraboschi investigated the buckling behavior of laminated glass (two layers of glass joined by an elastomeric interlayer to form a unit) numerically and experimentally $[17,18]$. The obtained results discovered the role of lamination on buckling and provided guidance for using laminated glass as compressive members. To appropriately simulate the nonlinear buckling behavior of space structures, the authors reviewed some related references, for example, buckling/stability analysis of cable-braced grid shells $[19,20]$ and nonlinear stability analyses of hybrid grid shells [21,22,23] and hybrid barrel vault roof [24,25].

The remainder of this paper will be organized as follows. First, how the load-carrying characteristics of an individual member are changed before and after buckling is discussed. Second, an approach to detect member overall buckling is proposed based on the deviation in strain along the member, and justifications are made for applying the proposed approach in cases where strain gauges are deployed during the service life of a structure. Third, the application scope of the proposed approach is discussed. Next, numerical simulations are conducted to validate the proposed approach. Finally, conclusions and future research are presented.

\section{Change in Load-carrying Characteristics of a Member Before and After Buckling}

The proposed approach to detect buckling in this study is based on the following observation: when an individual member in a space grid structure buckles in an overall sense, a large bending stress is developed, and the load-carrying characteristics of the member change before and after buckling, from the axial stress being dominated to the bending stress being dominated. The domination of the bending stress will result in the normal stress on the surface of the member at different cross sections to significantly deviate from each other, which lays the foundation of the proposed approach. This section will justify the above observation by taking a space grid structure (see Fig. 1) as an example. The description of boundary conditions of this structure can be referred to Note 1) in Fig. 4.

Assume that the compression members in this structure are straight and they are pinconnected, and a downward load is applied at each end joint of each member on the top layer of the structure (no load acts between the two end joints of each member), as shown in Fig. 1c). Consider a potentially buckled member, a horizontal compression member (Member CX1) around the center of the upper layer, as indicated in Fig. 1. This member is subjected to two horizontal compressive forces $(\mathrm{P})$ at the two end joints, and all forces in the other two directions can be taken as lateral elastic restraints, as shown in Fig. 2a). Before the member buckles, the member is almost straight and thus the member is mainly subjected to an axial compressive force. Accordingly, the normal stress of the member is mainly due to axial compression. Through a basic force analysis, the axial force remains uniform along the member. Therefore, the normal stress in the member almost keeps uniform along the member. Accordingly, the normal strain on the surface almost keeps constant along the member. 
It is worth noting that even before a member buckles, a small bending stress exists in the member and contributes to the total normal stress due to the presence of lateral elastic restraints from other members. Therefore, theoretically, the normal stress in the member is the sum of the stress due to axial compression (referred to axial stress, $\sigma_{a}$ ) and the stress due to bending (referred to bending stress, $\sigma_{b}$ )

$$
\sigma_{t}=\sigma_{a}+\sigma_{b}
$$

However, $\sigma_{b}$ is very small compared to $\sigma_{a}$ and is negligible before the member buckles. On the contrast, for an ideal independent single compression member, only an axial stress exists in the member before this member buckles. This is a big difference in buckling behavior between an independent single compression member and a compression member in a structural system, a two-way beam system (the case in this study). This has been validated by numerical simulation results presented in Section 5.1.3.2, as shown in Fig. 8.

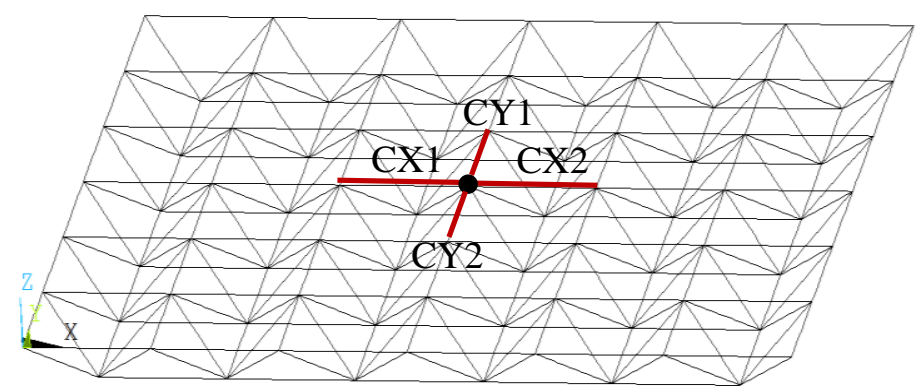

a) 3-D view

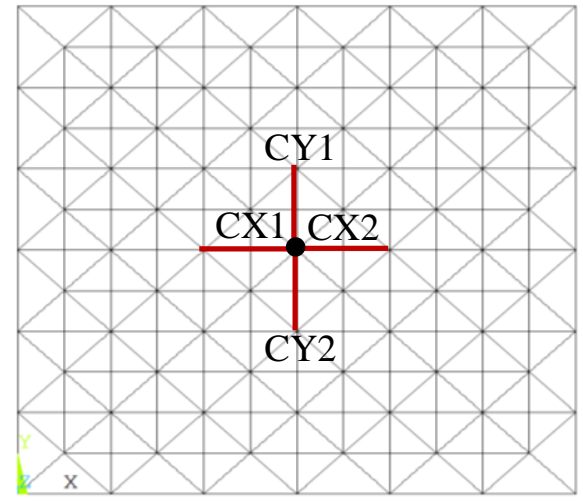

b) Plan view

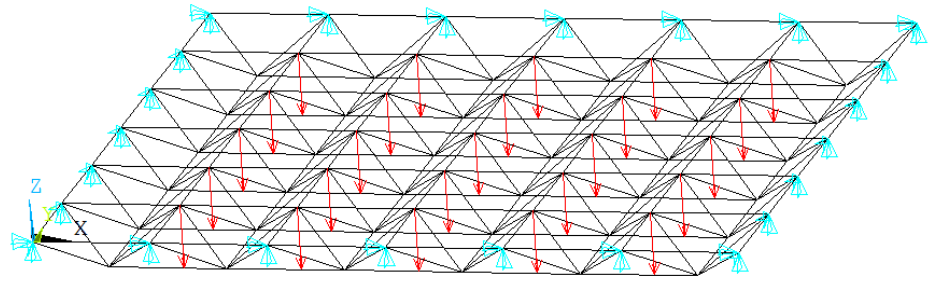

c) Boundary conditions (blue restraints) and external loading (red arrows)

Fig. 1 A space grid structure

For this type of structure, as the magnitude of external loads gradually increases, the internal compressive forces in members increase. When the internal compressive force in any member reaches its critical buckling load, that member will buckle. Once the member buckles, it suddenly bows, as shown in b1) of Fig. 2b). Besides an axial stress due to axial compression and a small bending stress due to lateral elastic restraints, a large bending stress is developed due to the bending deformation caused by buckling, as shown in b2) of Fig. 2b). At this stage, the normal stress in the member can also be expressed as Eq. (1). However, the bending stress $\left(\sigma_{b}\right)$ starts to become significant and dominates the total normal stress, leading the total normal stresses at two different sections (e.g., Sections A and B in Fig. 2b)) to deviate from each other significantly, which lays the foundation of the proposed approach. The following explains why a buckling can cause the total normal stresses at two different sections to deviate from each other. 
Please note that the stress/strain in the following deviation always refer to the normal stress/strain on the surface of the member on the concave side.

The axial stress in Eq. (1) is expressed as

$$
\sigma_{a}=\frac{N}{A}
$$

where $N$ is the axial compressive force in the member and $A$ is the cross-sectional area of the member.

The bending stress in Eq. (1) is expressed as

$$
\sigma_{b}=\frac{M c}{I}
$$

where $c$ is the transverse distance from the neutral axis to the concave surface of the member, $I$ is the moment of inertia of the cross section, and $M$ is the bending moment at the cross section where the stress is to be evaluated.
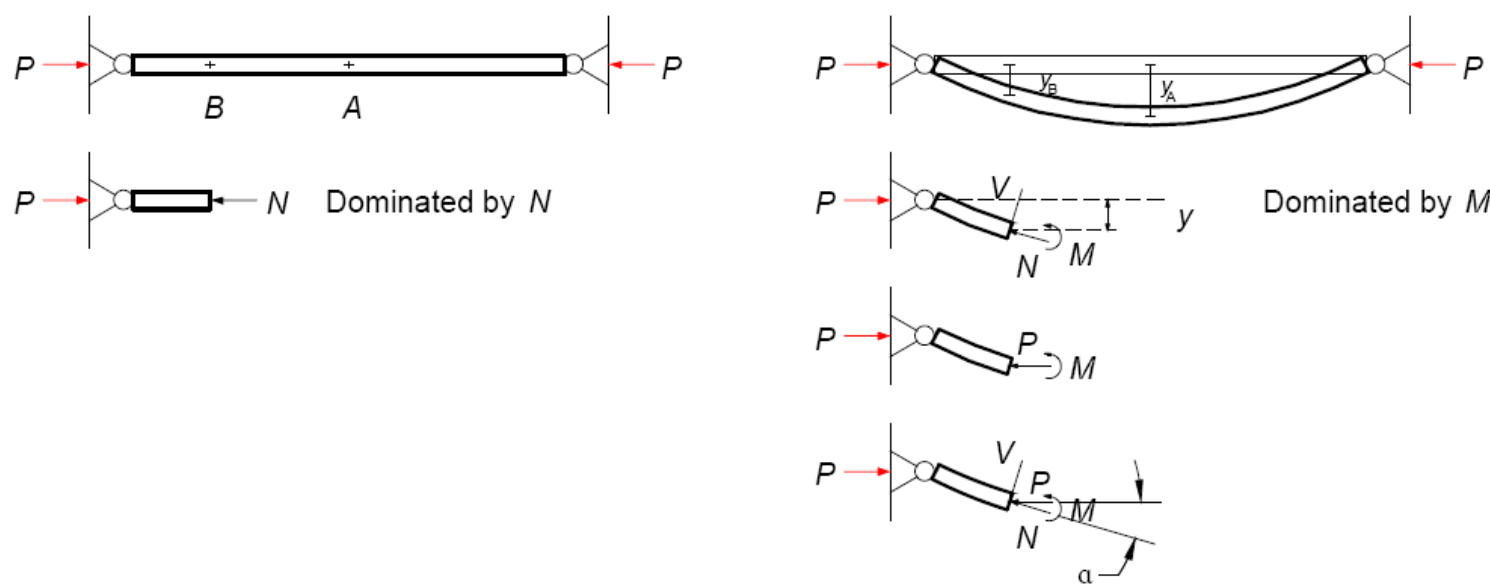
a) before buckling
b) buckled

Fig. 2 Schematic diagram of change in load-carrying characteristics due to buckling (lateral elastic restraints are omitted in this figure)

By performing a basic force analysis, $M$ and $N$ are a function of $P$ and can be obtained from the equilibrium of the free body shown in b3) of Fig. 2b). At the cutting section, to balance the external force $P$, the resultant force acting on this cross section should equal $P$, and the resultant moment should be $M=P y$. By adding the resultant force $P$ into b2) of Fig. 2b), as shown in b4) of Fig. 2b), the axial compressive force $N$ can be obtained as

And the shear force can be obtained as

$$
N=P \cos \alpha
$$

$$
V=P \sin \alpha
$$

Substituting Eq. (4) into Eq. (2) yields

Substituting $M=P y$ into Eq. (3) yields

$$
\sigma_{a}=\frac{P \cos \alpha}{A}=\frac{P}{A} \cos \alpha
$$

$$
\sigma_{b}=\frac{P y c}{I}=\frac{P}{I / c} y
$$

Substituting Eq. (6) and Eq. (7) into Eq. (1) yields

$$
\sigma_{t}=\sigma_{a}+\sigma_{b}=\frac{P}{A} \cos \alpha+\frac{P}{I / c} y
$$


Associated with a specific load $(P)$, the deviation in stress between two sections can be expressed as

$$
\Delta \sigma_{t}=\Delta \sigma_{a}+\Delta \sigma_{b}=\frac{P}{A}\left(\cos \alpha_{A}-\cos \alpha_{B}\right)+\frac{P}{I / c}\left(y_{A}-y_{B}\right)
$$

where subscripts "A" and "B" denote the two sections of Member CX1, Section A and Section B (see Fig. 2). Section B is located close to one end of the member and Section A is located close to the center of the member.

From Eq. (9), the deviation in stress is contributed from two effects. The first contribution is from the effect of axial compression. From Section B to Section A, the angle between the longitudinal axis (the tangent line of the deformation curve) of the member and the horizontal axis $(\alpha)$ gradually decreases from an acute angle to 0, i.e., $\alpha_{B}>\alpha_{A}$. Therefore, the first term of Eq. (9), $\frac{P}{A}\left(\cos \alpha_{A}-\cos \alpha_{B}\right)$, is greater than zero. Actually, $N$ gradually increases from a smaller value to $P$ from the left end to the center of the member (from Eq. (4)), so does $\sigma_{a}$ (from Eq. (6)).

The second contribution is from the effect of bending. From one end to the center (from Section B to Section A), the bending stress gradually increases, because the moment arm increases, i.e., $y_{A}>y_{B}$, as shown in b1) of Fig. 2b). Thus, the second term of Eq. (9), $\frac{P}{I / z}\left(y_{A}-y_{B}\right)$, is greater than zero. Therefore, $\sigma_{a}$ and $\sigma_{b}$ have the same change tendency, which forms the deviation in stress between sections.

As a consequence, the total normal stresses at different cross sections along the member deviate from each other due to buckling. To be specific, it increases along the member from one end to its center once buckling occurs, while the total normal stress remains the same along the member before buckling, which lays the foundation of the proposed approach.

After a further investigation, the deviation in $\sigma_{a}$ between cross sections is much smaller than the deviation in $\sigma_{b}$, because the angle $\alpha$ and its variation along the member due to buckling are both very small. On the contrary, the deviation in $\sigma_{b}$ between sections is significant due to the large deformation caused by buckling. Therefore, $\sigma_{b}$ dominates the deviation in the normal stress along the member, which will be demonstrated by numerical simulation results.

\section{Buckling detection based on the deviation in normal strain along the member}

Based on the above analysis, detecting buckling is to detect the deviation in normal stress along the member. For elastic buckling, the material works in its elastic regime at buckling and during the early stage of post-buckling, and thus normal strain has a similar change tendency along the member to normal stress. Therefore, detecting the occurrence of buckling is to detect the deviation in normal strain, for which we just need to deploy strain gauges on the members of interest. In practice, buckling occurs once the external load reaches its first buckling load, and the deformation due to buckling follows the first buckling mode shape, which is normally symmetrical or almost symmetrical. Therefore, to track the deviation in normal strain along the member, we just need to deploy two stain gauges in half of the member. If the two measured strains associated with the same time instant start to deviate from each other, it indicates that buckling initiates.
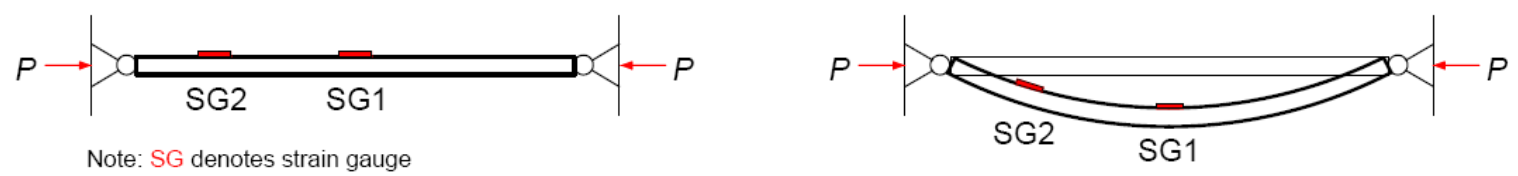
a) Before the member buckles, reading from SG1 equals that from SG2 theoretically b) Once the member buckles, reading from SG1 deviates from reading in SG2 significantly

Fig. 3 Deployment of strain gauges when implementing the proposed approach

To obtain the change in actual normal stress along the member in Eq. (9), strain gauges should be deployed before the member is assembled. For existing structures, stain gauges are usually deployed after construction and during the service life of the structure. Then, strain gauges can only measure the strains caused by the loads or effects applied after strain gauges are deployed. For this case, the following will justify that the strain gauges can pick up almost all the deviation in normal strain along the member and that the deviation in the measured strains between sections can directly indicate whether a member buckles or not.

Take a potentially buckled compression member as an example. Assume that the critical buckling load of this member is $10 \mathrm{kN}$ and the load acting on the member right before the strain gauges are deployed is $2 \mathrm{kN}$. When the load increases to any level lower than $10 \mathrm{kN}$, say $9 \mathrm{kN}$, the strain gauges can only pick up the strain caused by the load increase $(9-2=7 \mathrm{kN})$, instead of the strain caused by the total load $(9 \mathrm{kN})$. Since the member has not buckled yet and the member's internal force is mainly axial compression, at any load level, the strains/stresses at any two cross sections are almost equal to each other, and the two measured strains are almost equal to each other. Although the measured strains only represent the strains caused by the load increase (instead of the intrinsic strains in the member), they can still be used to determine that the member has not buckled yet.

When the total applied load reaches the critical buckling load, $10 \mathrm{kN}$, the member buckles. At this time, the member bends significantly and a large bending stress is introduced. Because this large bending stress at any cross section only develops at buckling, assuming that strain gauges are deployed at any time before buckling, all bending strain caused by buckling will be picked up by strain gauges, although the strain gauges can only pick up part of the strain caused by the axial compression. Since the bending stress dominates the deviation in stress along the member, as discussed in the previous section, the deviation in measured strains by strain gauges can almost reflect the total deviation in stress between sections induced by buckling. For those members that do not buckle, no large bending stress is developed and normal stress is mainly caused by axial compression. And thus, no significant deviation in strain is measured. Therefore, the measured strains can be used to determine whether a member has buckled or not.

As long as strain gauges are deployed on the members of interest before buckling, no matter how late they are deployed, the strain gauges will pick up all the bending stress/strain due to buckling, and the proposed approach will be able to detect buckling.

\section{Implementation of the Proposed Approach}

Since Eq. (3) is only applicable to linear systems, the above deviation strictly holds true for the early stage of elastic buckling. At the later stage of buckling, Eq. (3) may represent the linearized bending stress due to large deformation caused by buckling. When elastic buckling occurs, the external load may be very low and the members are under-stressed, and thus strains are small, leading to small displacements. Thus this type of instability does not give any visual indication before its occurrence. In addition, a structural member failure at a low level of loading may not be expected by maintenance crew. However, if undetected timely, individual member buckling may propagate into a failure of the overall structure. This study provides a simple and 
effective approach to detect elastic buckling of members and thus has a great potential to benefit the research communities of SHM and structural stability as well as the general public.

For some space grid structures, members may be pin-connected with an initial curvature caused by different factors, such as distributed self-weight along the member or fabrication/installation errors; for other space grid structures, members may be connected rigidly. In these cases, even before buckling, the bending stress due to lateral elastic restraints from other members may be comparable to axial stress. However, the stress/strain deviation between sections due to this bending effect is much smaller than that due to the bending effect caused by buckling, as will be illustrated in the following numerical simulation results. As long as strain gauges are deployed before buckling, all the bending stress induced by buckling will be picked up by strain gauges, which is the same as the discussion in the previous section. In this case, only part of the bending stress developed before buckling can be picked up by strain gauges. Since not all of them can be picked up, the stress/strain deviation caused by factors other than buckling is actually suppressed, which facilitates in detecting buckling.

In the above derivation, it is assumed that the normal strain is measured on the concave side of the member when buckling. If the normal strain is measured on the convex side of the member when buckling, considering that $\Delta \varepsilon_{a}$ is negligible and $\Delta \varepsilon_{b}$ is significant, buckling can still be detected from the deviation in measured normal strains.

\section{Numerical Validation}

Consider a square-on-square staggered double-layer space grid structure, as shown in Fig. 4. It is 6-bay by 6-bay, and $48 \mathrm{~m}$ long, $48 \mathrm{~m}$ wide and $3 \mathrm{~m}$ high. These dimensions meet the design requirements for space grid structures specified in [1]. It is assumed to be made of A36 steel with a density of $7.8 \times 10^{3} \mathrm{~kg} / \mathrm{m}^{3}$, a modulus of elasticity $(E)$ of $200 \mathrm{GPa}$ and a Possion's ratio of 0.26 . The yield stress of A36 steel $\left(F_{y}\right)$ is $250 \mathrm{MPa}$. The stress-strain curve of the steel used here is assumed to be bilinear, as shown in Fig. 5. The tangent modulus that describes the steel behavior beyond the elastic region is set $0.03 E(6 \mathrm{GPa})$. On the upper layer, this structure is pinned in three directions at the four corners and supported by a roller at each peripheral joint (details are specified in Fig. 4). All members are tubular. The outer diameter and thickness of the members on the upper layer are $114 \mathrm{~mm}(D)$ and $5 \mathrm{~mm}(t)$, respectively; $108 \mathrm{~mm}(D)$ and $4 \mathrm{~mm}(t)$ for the members on the lower layer; and $76 \mathrm{~mm}(D)$ and $3.5 \mathrm{~mm}(t)$ for the members between two layers. All of these three types of tubular members satisfy $\frac{D}{t} \leq 0.11 E / F_{y}$, and thus local buckling of members will not occur before overall buckling [1]. Assume that only flexural buckling occurs. 


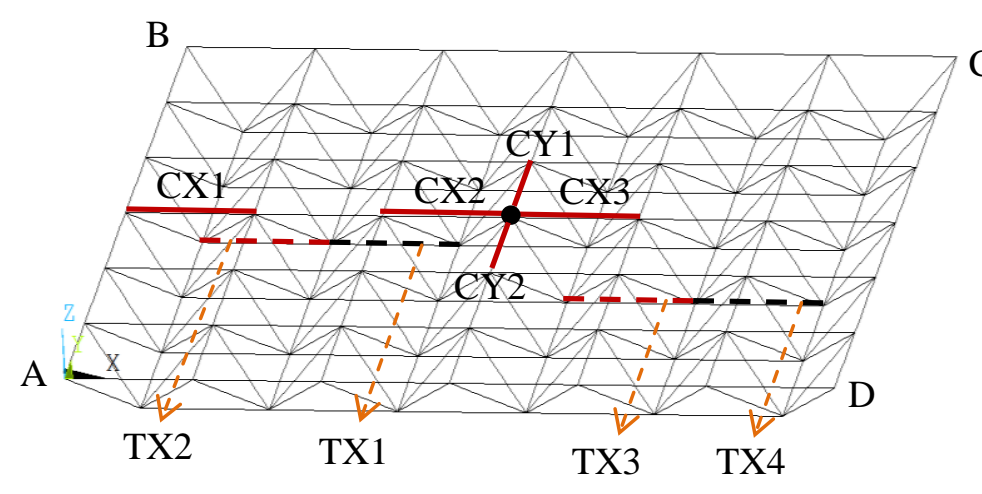

a) 3-D view

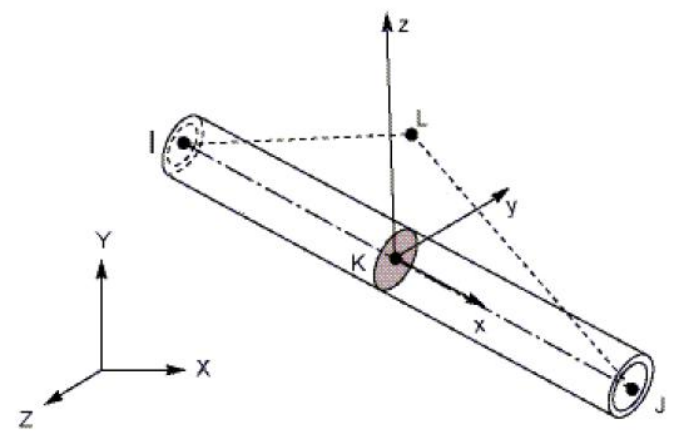

c) Local coordination of a member

\section{$\mathrm{C}$ B}

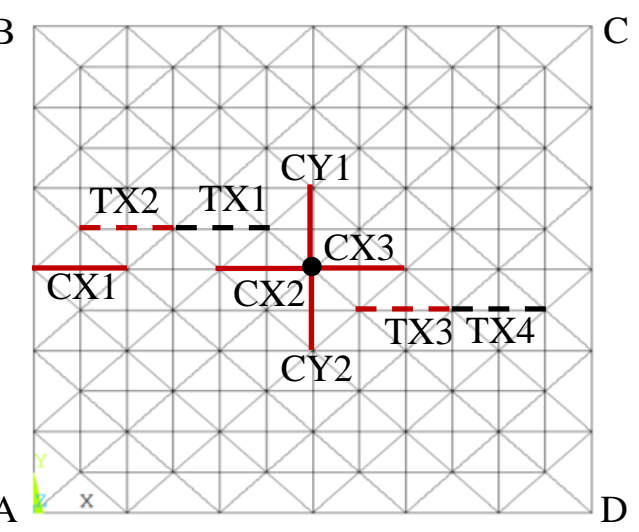

b) Plan view

Fig. 4 Finite element model (FEM) of a space grid structure and locations of some representative members

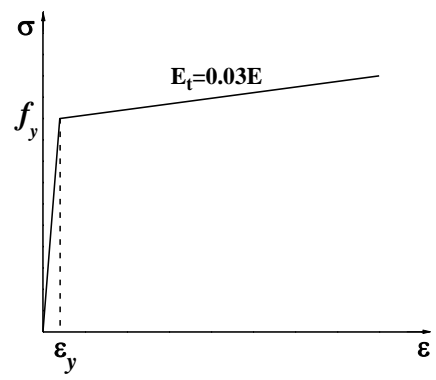

Fig. 5 The stress-strain curve of the steel used in this study

Three finite element models of this structure are developed to consider different connections between members and loading situations using ANSYS. In all the three models, members are modeled using BEAM188, and each member is meshed into 13 elements. Previous research has demonstrated that the first buckling mode shape (designated as $\left\{\varphi_{1}\right\}$ ) obtained from an eigenvalue buckling analysis may provide the greatest destabilizing effect [26]. Thus, the amplitudes of $\left\{\varphi_{1}\right\}$ with a scaling factor are applied to the corresponding nodes to displace them from their nominal locations, which follows the "direct modeling of imperfections", specified in Article 2a of Section C2 in Specification for Structural Steel Buildings [27].

For each model, a nonlinear buckling analysis based on the arc-length method is conducted to track the whole process of losing stability, including both the pre- and post-buckling behaviors 
of the structure, and to validate the proposed approach to detect buckling. To facilitate in setting the maximum load for the arc-length method and to obtain the first buckling mode shape to include geometric imperfection in the model [26, 27], an eigenvalue buckling analysis is conducted before the nonlinear buckling analysis.

\subsection{Model 1: Members are ideally pinned and only external loads are considered}

In this model, member ends are assumed to be ideally pinned, i.e., the restraints at the three rotational DOFs of each joint are released. Assume that the self-weight gravity load of each member is negligible and only external concentrated loads with equal magnitudes act at each joint of the upper layer of this structure in the download direction, perpendicular to the plane of the upper layer.

\subsubsection{Classify the type of buckling}

If the stress just before buckling is less than the proportional limit stress of the material, the member woks in the elastic regime when buckling and the buckling is classified as elastic buckling. For elastic buckling, the classical Euler theory can be used to compute the critical buckling load $\left(P_{c r}\right)$ and the critical buckling stress $\left(F_{c r}\right)$ as follows [28]

$$
\begin{gathered}
P_{c r}=\frac{\pi^{2} E A}{\left(\frac{K L}{r}\right)^{2}} \\
F_{c r}=\frac{P_{c r}}{A}=\frac{\pi^{2} E}{\left(\frac{K L}{r}\right)^{2}}
\end{gathered}
$$

where $E$ denotes the modulus of elasticity; $A$ and $r$ are the area and radius of gyration of the cross section of the member; $L$ is the length of the member; $K$ is the effective length factor of the member, which depends upon the type of connection between members and the geometric properties of the member at its end [1,29]. In this case study, $K$ is taken as 0.95 according to the design guidance [1].

Buckling potentially takes place in the members that carry the maximum compressive forces. Since loads act downward on joints of the upper layer, the chord members in the upper layer are in compression. The chord members around the center of the upper layer carry the maximum compressive forces and will potentially first buckle. By substituting $E=2.0 \times 10^{11} \mathrm{~Pa}, K=0.95, L=8 \mathrm{~m}$ and $r=\sqrt{\frac{I}{A}}$ into Eq. (11), $F_{c r}$ is obtained as $50.8 \mathrm{MPa}$. For A36 steel, the proportional limit stress is $215 \mathrm{MPa}$. Therefore, the overall buckling in this case study is classified as elastic buckling.

\subsubsection{Eigenvalue Buckling Analysis}

Herein the structure is assumed to be an ideal linearly elastic structure, i.e., all initial imperfections are ignored and the steel is assumed to work elastically. "Eigenvalue Buckling Analysis" is selected as the Analysis Type in ANSYS. "BUCOPT" is selected as the eigenvalue extraction method. Ten eigenvalues and eigenvectors are extracted.

This analysis is based on the fact that the stiffness matrix becomes singular when the overall structure buckles. The general approach to obtain the critical buckling load $\left(P_{c r}\right)$ and the first buckling mode shape is to solve the following generalized eigenvalue problem [2].

$$
\left([K]+\lambda_{i}[S]\right)\left\{\varphi_{i}\right\}=\{\mathbf{0}\}
$$


where $[K]$ is the stiffness matrix; $[S]$ is called the stress stiffness matrix, which is the stiffness matrix when considering the stress caused by a pre-set load $(F)$ with an arbitrary magnitude as prestress. Therefore, the prestress effect in ANSYS must be activated in this analysis. $\lambda_{i}$ is the $i$ th eigenvalue that represents the scaling factor of load $F$, and the $i$ th buckling load is estimated as $\lambda_{i} F .\left\{\varphi_{i}\right\}$ is the $i$ th eigenvector, representing the deformation profile of the structure under the load of $\lambda_{i} F$.

The critical buckling load $\left(P_{c r}\right)$ normally refers to the buckling load associated with the lowest eigenvalue $\lambda_{1}$, i.e., $P_{c r}=\lambda_{1} F$. It is worth noting that the estimated $P_{c r}$ here is usually greater than the actual $P_{c r}$ due to the assumptions of perfection made in the eigenvalue buckling analysis. The first eigenvector $\left\{\varphi_{1}\right\}$ that is associated with $\lambda_{1}$ is the first buckling mode shape.

In this case, the pre-set load $(F)$ is $1 \mathrm{~N}$ at each joint on the top layer in the downward direction. The obtained $\lambda_{1}$ is 11474 . Accordingly, $\lambda_{i} F=11.47 \mathrm{kN}$. Associated with $\lambda_{1}$, there are eight different buckling mode shapes with a different top chord member buckled. A representative mode shape is presented in Fig. 6 from two different perspectives. In this buckling mode shape (designated as $\left\{\varphi_{1}\right\}$ ), a top chord member (indicated by "Blue" color) buckles in the plane of the upper layer. $\left\{\varphi_{1}\right\}$ will be used to update the original geometric model to include geometric imperfections into this model. Considering that $\left\{\varphi_{1}\right\}$ introduces an in-plane curvature to a member, the amplitudes of $\left\{\varphi_{1}\right\}$ with a scaling factor of 0.008 (1/1000 of the member length) are applied to the corresponding nodes to displace them from their nominal locations to obtain the updated finite element model.
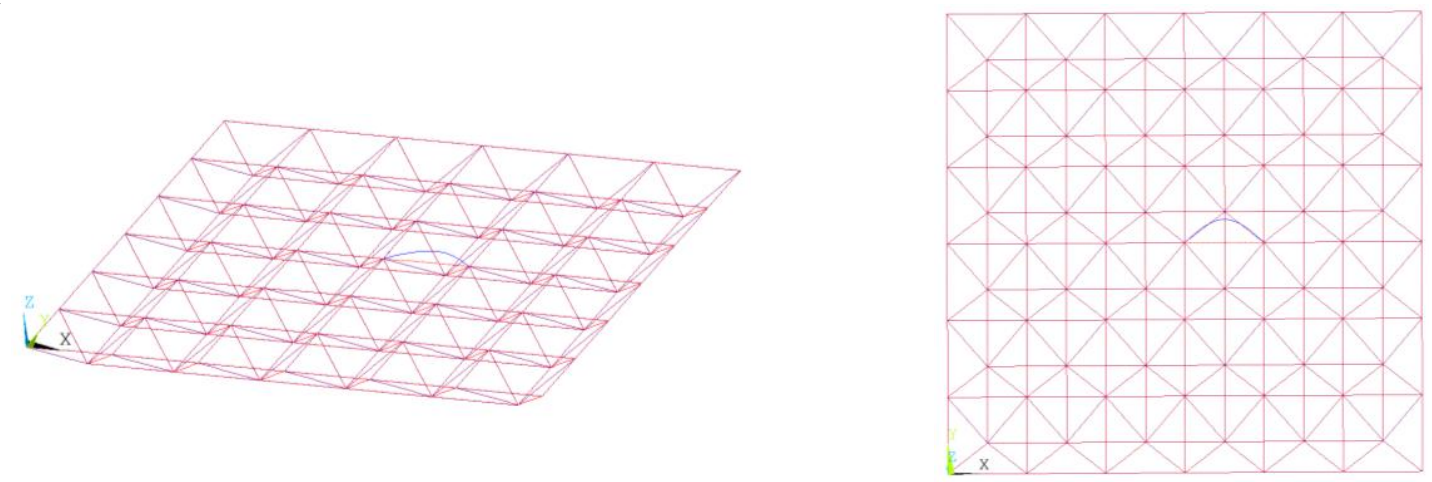

a) 3-D view

b) Plan view

Fig. 6 The first buckling mode shape

(Red for original configuration; blue for buckling mode shape)

\subsubsection{Nonlinear buckling analysis by the arc-length method}

A nonlinear buckling analysis based on the arc-length method is performed on the updated finite element model to investigate the pre- and post-buckling behavior of the structure. In ANSYS, "Static Analysis" is selected as the Analysis Type. Both material nonlinear effect (nonlinear stress-strain relationship) and geometric nonlinear effect (large displacements and rotations) are included in this analysis. Material nonlinear effect is applied by specifying the yielding strength as $250 \mathrm{MPa}$ and the tangential modulus as $6 \mathrm{GPa}$; geometric nonlinear effect is applied by turning "NLGEOM" on.

To perform a nonlinear buckling analysis is actually to gradually increment the applied loads until the solution begins to diverge [30]. In this study, the magnitude of the external load gradually 
increases from 0 to $28 \mathrm{kN}$. The upper bound value of the applied load in this nonlinear buckling analysis should be much greater than the critical buckling load obtained from the eigenvalue buckling analysis $\left(\lambda_{1}=11.47 \mathrm{kN}\right)$ in order to see the post-buckling behavior. Through this nonlinear buckling analysis, it is observed that the first buckled members include Members CY1 and CY2 and they buckle out of the plane of the upper layer. The following sections will present the structural response time histories in terms of deformation, stress and strain, respectively. Refer to Fig. 4 for locations of representative members in the structure.

\subsubsection{Load-displacement curves}

For space grid structures, buckling occurs to individual members. Since the members around the center of the upper layer carry the maximum compressive forces, they will potentially buckle earlier than others as the external load gradually increases. Here Member CY1 is taken as an example to investigate how buckling develops in a member. A member on the upper layer buckles about either the $y$ or $z$ axis of its local coordination (see Fig. 4c)). This can be reflected from a large displacement at mid-span of the member in the $z$ or $y$ direction, respectively. In this study, Member CY1 actually buckles out of the plane of the upper layer, about the $y$ axis of the local coordination of the member (see Fig. 4c)). Considering that how a member buckles is not known in advance, the displacements at mid-span of the member in both the $y$ and $z$ directions are extracted and presented in Fig. 7. For comparison, the displacements at mid-spans of a compression member that will not experience buckling (Member CX1, designated as "Unbuckled compression member" in Fig. 7 and two tension members (Members TX1 and TX2, designated as "Tension Member 1" and "Tension Member 2" in Fig. 7 will also be presented. Member CY1 is designated as "Buckled compression member" in Fig. 7.

Figure $7 b$ ) presents the displacements in the $z$ direction. At the beginning of loading, the displacements at mid-spans of all four members linearly increase with the external load. Although the member has not buckled yet, lateral displacements are observed. This is due to the presence of lateral elastic restraints from other members. When the external load reaches 11.18 $\mathrm{kN}$, as indicated by the first blue circle from origin in Fig. 7b), the displacement at mid-span of Member CY1 starts to become nonlinear and a softening behavior is observed; in addition, the displacement on Member CY1 starts to become much greater than that on the unbuckled compression member and those on the two tension members. The above two observations indicate the onset of buckling, and the condition of instability that follows. Associated with the load of $11.18 \mathrm{kN}$, the maximum normal stress is $-46.62 \mathrm{MPa}$ (compression) and the maximum von Mises stress is $46.62 \mathrm{MPa}$, which are much smaller than the proportional limit stress of A36 steel (215 MPa). It verifies that the member experiences elastic buckling.

The stress results show that, as the magnitude of external loads increases to $21.40 \mathrm{kN}$, as indicated by the second blue circle from origin in Fig. 7b), the outmost fibers at the midspan of Member CY1 yield, and the maximum normal stress in the longitudinal direction reaches -249.84 MPa (compression) and the maximum von Mises stress both reaches 249.84 MPa. As the external load reaches $28.00 \mathrm{kN}$, as indicated by the peak in the graph, the structure reaches its loading capacity.

Figure 7a) presents the displacements at mid-spans of the same representative members in the $y$ direction. Associated with each load level, the magnitude of displacements on all four members is very small, at the order of magnitude of $10^{-3}$, much smaller than those in the $z$ direction; and the deviation in displacements between all members is much smaller than that in the $z$ direction. By 
comparing Figs. 7a) and 7b), it verifies that Member CY1 buckles about the $y$ axis of the local coordination.

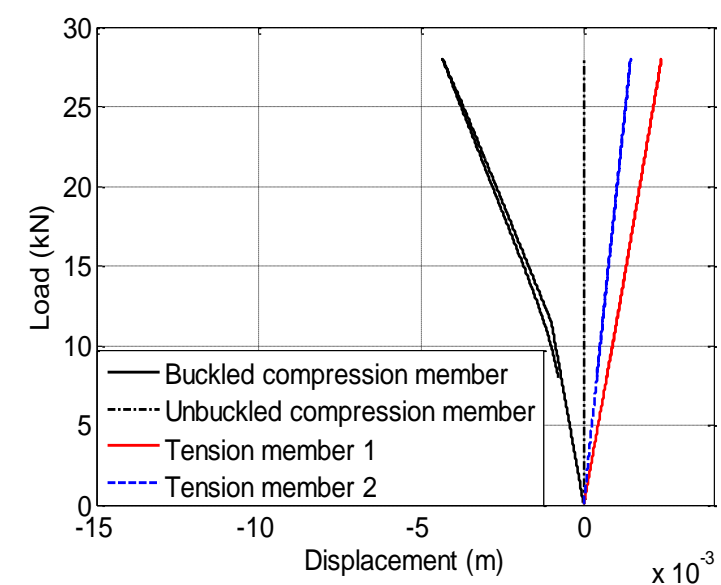

a) Displacements at mid-spans in $y$ direction

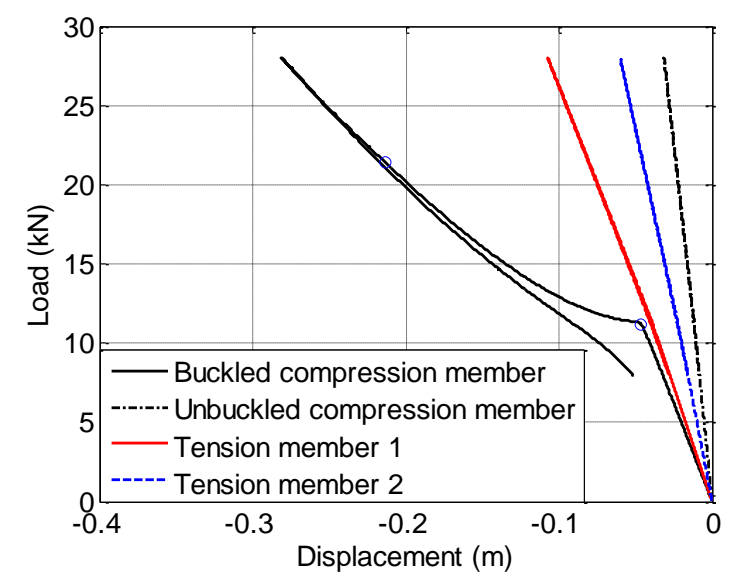

b) Displacements at mid-spans in $z$ direction

Fig. 7 Load-displacement curves

From Fig. 7, after Members CY1 and CY2 buckle, the external load can be increased from $11.18 \mathrm{kN}$ to $28.00 \mathrm{kN}$. It suggests that the structure can still resist more loads after two members buckle. Therefore, if buckling is detected timely, people still have time to respond to avoid a catastrophic structural failure. This justifies the significance of the research on detecting buckling. Please note that the curves in Fig. 7 are just to present how buckling is developed and that the proposed approach to detect buckling in this study is not based on the load-displacement curves. In fact, the load may not be measured and thus the complete curve may not be obtained in practice. In addition, Fig. 7 serves a function to indicate the type of instability. From the linear behavior of the load-displacement curve before buckling and the nonlinear behavior after buckling, this buckling is classified as bifurcation instability.

\subsubsection{Validation of Change in Load-carrying Characteristics}

To verify that buckling introduces a large bending stress and the load-carrying characteristics of a potentially buckled member change due to buckling, Figs. 8 and 9 present the stress and strain time histories at two cross sections of two representative members, a potentially buckled compression member (Member CY1) and an unbuckled compression member (Member CX1). The stresses presented here are the maximum stresses at the interested sections due to each type of effect, i.e., axial compression, bending about the $y$ axis and bending about the $z$ axis. They may not be associated with the same spot on the cross section. In each figure, black graphs are for Section A, and red graphs are for Section B. Section A is located at the mid-span of the member, and Section $\mathrm{B}$ is located close to one end of the member, as shown in Fig. 2.

The stress time histories for Member CY1 are presented in Fig. 8a). In this figure, the load substep at which buckling occurs is indicated by a blue circle. As seen in this figure, before buckling, the stress is dominated by axial compression; although there exists bending stress due to the presence of lateral elastic restraints from other members, as can be observed from a zoom-in figure of Fig. 8a), the bending stress is too small to be negligible compared to axial stress. Once this member buckles, the bending stress quickly exceeds the axial stress and becomes much greater than 
the axial stress. This verifies that the load-carrying characteristics of the member change before and after buckling, from the axial stress being dominated to the bending stress being dominated. Here, the bending stress about the $y$ axis is much greater than that about the $z$ axis, which is consistent with the fact that Member CY1 buckles about the $y$ axis.

By comparing the axial stresses at Sections A and B in Fig. 8a), at any time (load substep) before buckling, the axial stresses at $\mathrm{A}$ and $\mathrm{B}$ are exactaly equal to each other. Once it buckles, it is observed that: 1) the stresses due to bending about the $y$ axis at A and B deviate from each other significantly, and the stress at $\mathrm{A}$ is much greater than the stress at $\mathrm{B}$ at any time, which is consistent with the discussion related to Eq. (7). Although there exists a deviation in the stress due to bending about the $z$ axis, this deviation is small, because buckling mainly causes the bending about the $y$ axis; 3) If the figure is zoomed in, it is found that the axial stresses at A and B also deviate from each other. To be specific, the axial stress at $\mathrm{A}$ is greater than that at $\mathrm{B}$, which is consistent with the discussion related to Eq. (6). However, this deviation is too small to be negligible compared to the deviation in bending stress, which verifies that the deviation in bending stress dominates the total deviation in stress.

Figure 9a) presents the strain time histories of Member CY1 due to each effect. The strain time histories have a similar tendency as stress, except that the axial strains between A and B start to deviate significantly at Load Substep 494. Actually, the material at mid-span (Section A) yields at this load substep. At this time, $E$ is reduced from $200 \mathrm{GPa}$ to $6 \mathrm{GPa}$ at Section A, while $E$ at Section $\mathrm{B}$ remains the same because no material yielding occurs to Section B. Therefore, from this load substep on, under similar stresses at Sections A and B, the strain at A deviates from the strain at B.

For comparison, the stress time history of a compression member that did not experience buckling is presented in Fig. 8b). Among all load substeps, there only exists axial compressive stress, and no bending stress is introduced because this member did not buckle. It verifies that a large bending stress is developed only when a compression member buckles. By comparing the axial stresses at $\mathrm{A}$ and $\mathrm{B}$, no deviation is observed, which means that the stress is uniform along the member, which is expected for an unbuckled member. For this member, the change tendency of the strain time history during the whole loading process is similar to that of the stress time history. No deviation in the normal strain between A and B is observed (see Fig. 9b)).

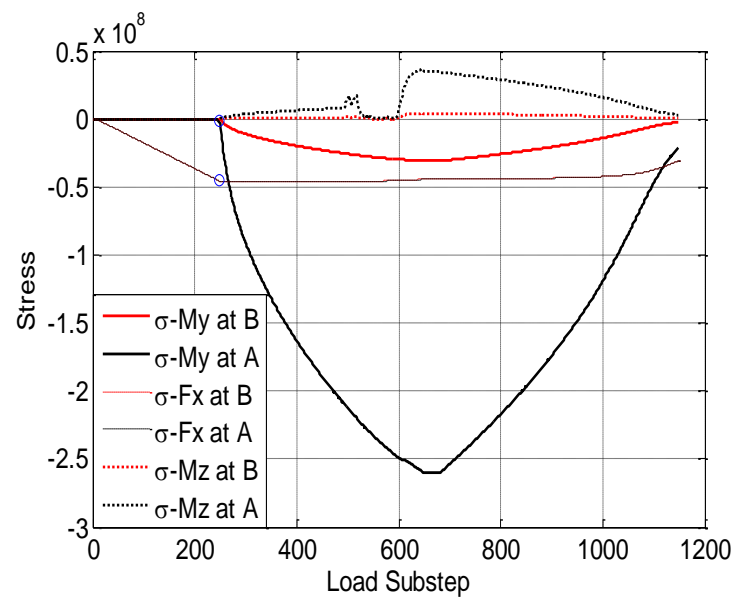

a) Potentially buckled compression member (Member CY1)

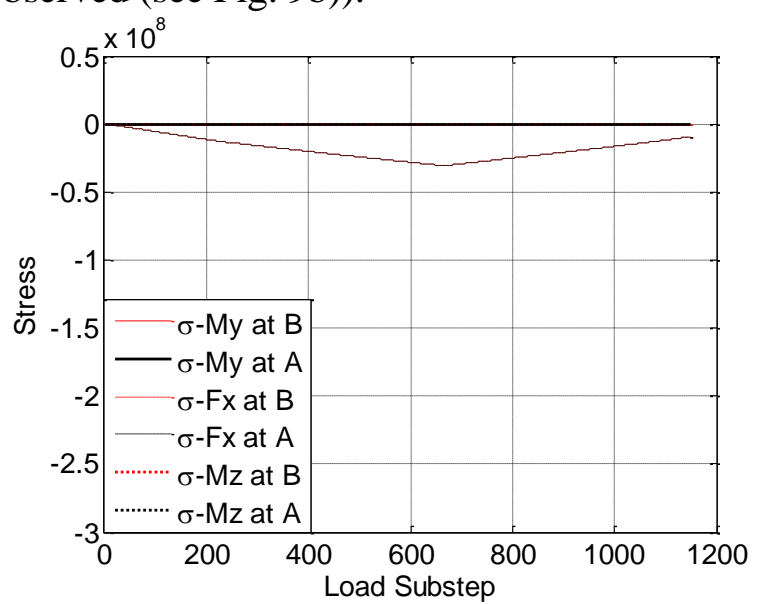

b) Unbuckled compression member (Member CX1)

Fig. 8 Time histories of stress due to each effect 


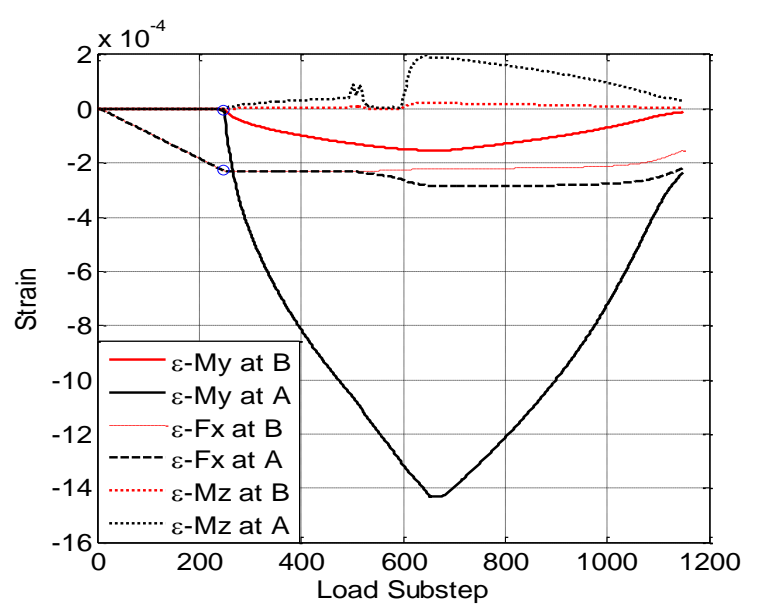

a) Potentially buckled compression member

(Member CY1)

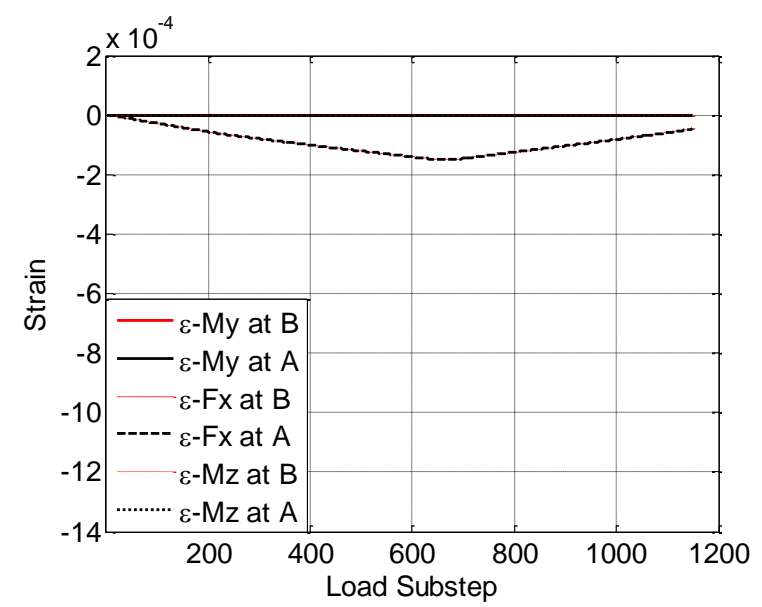

b) Unbuckled compression member (Member CX1)

Fig. 9 Time histories of strain due to each effect

\subsubsection{Validation of the Proposed Approach to Detect Buckling}

The proposed approach detects buckling by identifying the deviation in normal strain on the surface of members. To demonstrate the effectiveness of this approach, the time histories of the total normal strains on the surface of three representative members (CY1, CX1 and TX1) are extracted and presented. Members CY1 and CX1 are in compression, and TX1 in tension. Among these three members, only Member CY1 buckles as the load increases. The stain time history of each member is presented in Figs. 10-12, respectively.

Each figure presents the time histories of strains at two cross sections (Sections A and B) of each member against time (denoted by load substeps). From Fig. 10, at the beginning of loading, the strains at the two sections are identical to each other, as the member is working in the elastic regime and no buckling has happened yet. As the external load increases, the strains at the two cross sections start to deviate from each other, as indicated by the first blue circle from the origin. This is because the load reaches the critical buckling load and the member buckles. This is consistent with the theoretical analysis in the previous section. At this time, the maximum stress in the member (at mid-span) in the longitudinal direction is $-46 \mathrm{MPa}$ and the von Mises stress are both $46 \mathrm{MPa}$, which are smaller than $215 \mathrm{MPa}$. As the load further increases, the material at Section A starts to yield, as indicated by the second blue circle. At this time, the stress at the mid-span reaches $249.84 \mathrm{MPa}$. The above verifies that buckling causes the deviation of normal strain along the member.

Figure 11 presents the strain time history of an unbuckled compression member (Member CX1). As shown in this figure, the strains at the two cross sections are very small and remain exactly the same as time evolves. Actually, although this member is in compression, the stress is too small to cause this member to buckle. Figure 12 presents the strain time history of a tension member (Member TX1). From this figure, although slightly bigger strains are observed, both strains at the two cross sections remain the same as time evolves. Actually, this member is located in the lower layer and only carries tensile forces. Members under tension will never fail by buckling unless the internal forces are reversed to compression due to internal force redistribution. 
All the above results show that a significant deviation in normal strain along the member is observed only in the buckled member, validating the effectiveness of the proposed approach. In this case study, the strain time histories are used. By no means, complete strain time histories are not required when implementing this approach in practice. Strains associated with several time instants from both pre- and post-buckling stages would be sufficient.

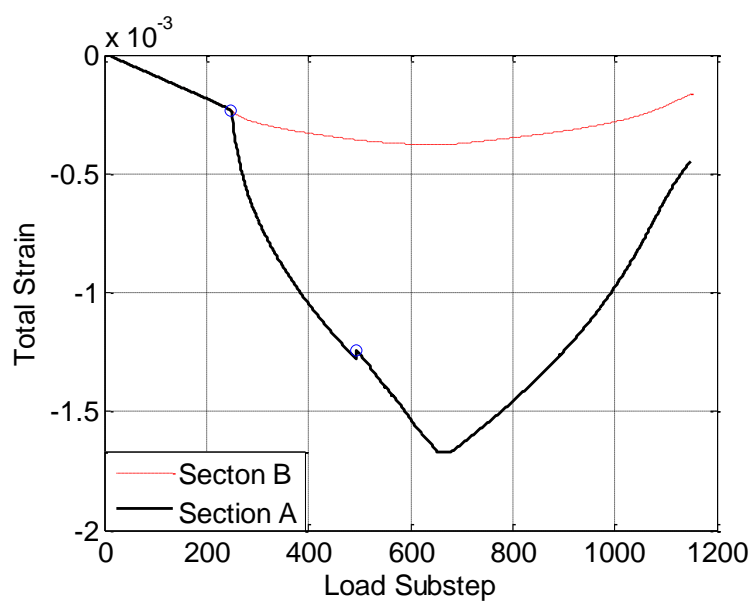

Fig. 10 Strain time history of a potenially buckled compression member (Member CY1) in Model 1

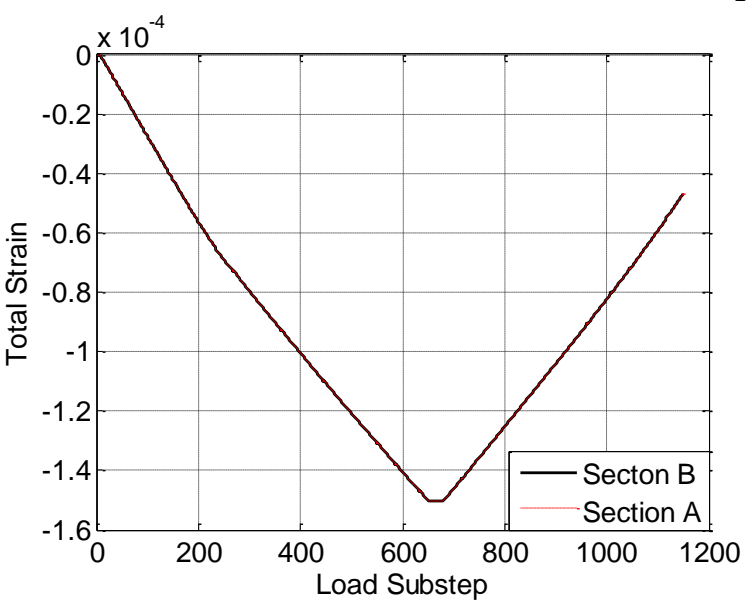

Fig. 11 Strain time history of an unbuckled compression member (Member CX1) in Model 1

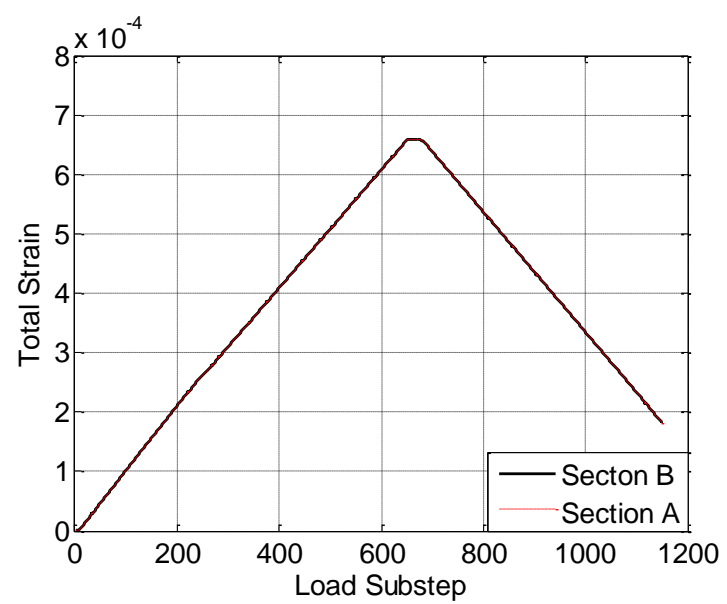

Fig. 12 Strain time history of of a tension member (Member TX1) in Model 1

\subsection{Model 2: Members are pin-connected and both self-weight and external loads are considered}

This model is the same as Model 1 except that self-weight gravity load of each member is considered in this model. That is to say, there are distributed gravity loads acting between two end joints of each member. Same as Model 1, the buckling in this model is classified as elastic buckling.

\subsubsection{Eigenvalue Buckling Analysis}

Although both the self-weight gravity load $(G)$ and externally applied loads are considered, because $G$ is constant, eigenvalue $\lambda_{1}$ can only be applied to the externally applied load that is 
variable [31]. To obtain $P_{c r}$, a number of eigenvalue buckling analyses are conducted by keeping $G$ remain the same and adjusting the magnitude of externally applied loads until $\lambda_{1}$ reaches 1.0. Then, the externally applied load will be the critical buckling load. In this case, the externally applied load associated with $\lambda_{1}=1.0$ is $6.2 \mathrm{kN}$, which is much lower than $\lambda_{1}(11.47 \mathrm{kN})$ in Model 1. This is because self-weight has stressed the member before external loads are applied.

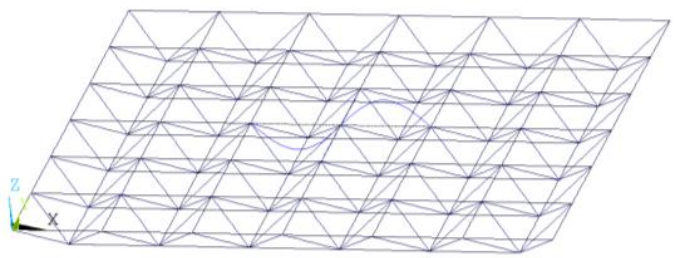

a) 3-D

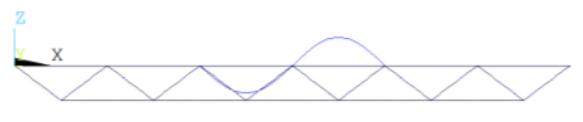

b) Elevation

Fig. 13 First buckling mode shape of Model 1

Associated with the critical buckling load of $6.2 \mathrm{kN}$, there are eight different buckling mode shapes with different members buckled. Figure 13 presents a representative buckling mode shape, in which two members buckle out of the plane of the upper layer. This buckling mode shape will be used to update the finite element model to include initial geometric imperfection.

\subsubsection{Nonlinear buckling analysis based on the arc-length method}

As mentioned before, the nonlinear buckling analysis based on the arc-length method is actually to constantly increment the applied loads until the solution begins to diverge. Although both the self-weight gravity load and external loads are considered here, the incremental increase is only applied to the external loads, as the gravity load should remain the same all the time. Therefore, two load steps are applied in this analysis. Load Step 1 is the gravity load, which is in the form of a step load. Load Step 2 is the external loads applied to each joint of the upper layer. In Load Step 2, the load magnitude gradually increases from 0 to $8.8 \mathrm{kN}$. The arc-length method is only applied to Load Step 2. The nonlinear buckling analysis shows that CX1 buckles out of the plane of the upper layer. Also, other members around the center buckle out of the plane of the upper layer.

Here we assume that we deploy strain gauges after the structure is assembled and before external loads are applied. Then, the strain gauges only pick up the strains caused by Load Step 2. The obtained structural responses (displacement, stress and strain) from the nonlinear analysis are actually the intrinsic properties caused by all loads applied to the structure (both Load Step 1 and Load Step 2). The strains picked up by strain gauges can be obtained by deducting the responses due to self-weight gravity load (Load Step 1) from the total responses (intrinsic) due to both Load Step 1 and Load Step 2. In the following, all presented responses are due to Load Step 2.

\subsubsection{Load-displacement curves}

Figure 14 presents the load-displacement curves of the nodes in the middle of four representative members, a potentially buckled compression member (Member CX2), an unbuckled compression member (Member CX1) and two tension members (Members TX1 and TX2). The displacements at mid-spans in both the $y$ and $z$ directions (in the local coordination system shown in Fig. 1c)) are presented. Figure 14b) presents the displacements in the $z$ direction. At the 
beginning of loading, the displacements of all four members approximately linearly increase with the external load even before buckling occurs. The slight curvature of the graphs is due to the presence of the uniformly distributed gravity load acting on the member, which introduces a bending stress before the member buckles. When the external load reaches $2.16 \mathrm{kN}$, as indicated by the first blue circle from origin in Fig. 14b), the displacement at mid-span of the potentially buckled member (Member CX2) starts to become nonlinear and a softening behavior is observed. It indicates the occurrence of buckling. At this time, the maximum normal stress in the longitudinal direction and von Mises stress are -105.16 $\mathrm{MPa}$ and 105.16 MPa, respectively, which are much smaller than the proportional limit stress of A36 (215 MPa). It verifies that the member experiences elastic buckling.

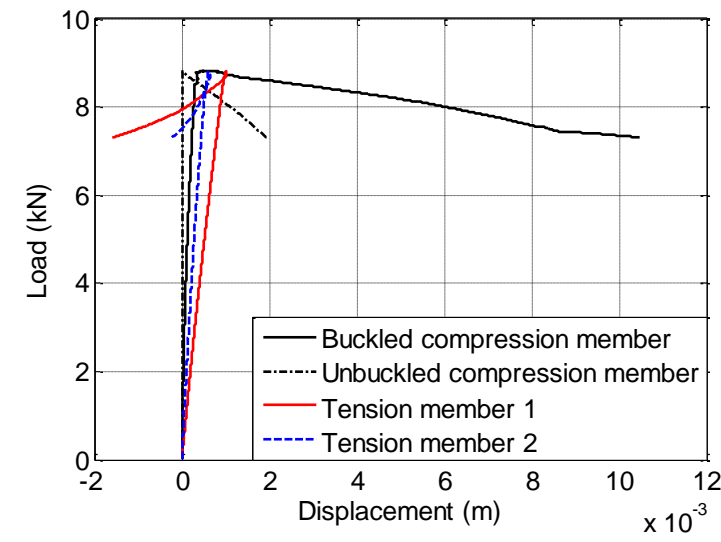

a) Displacement in the $y$ direction

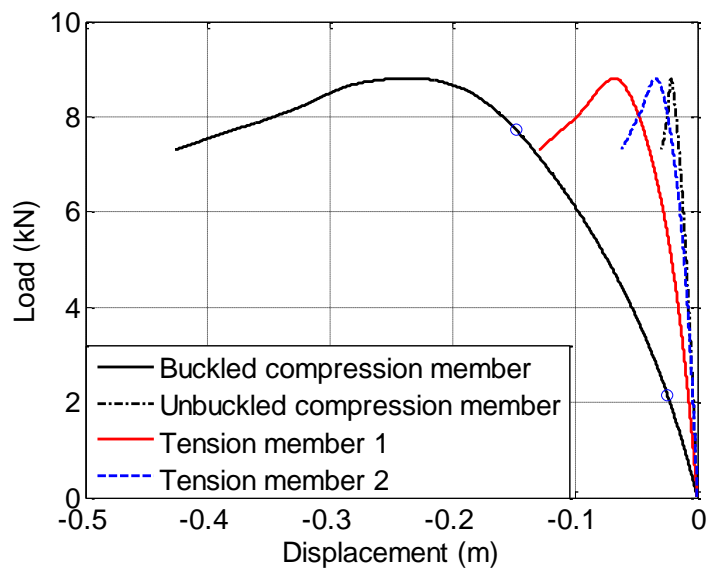

b) Displacement in the $z$ direction

Fig. 14 Load-displacement curves for Model 2

Further analysis shows that, when the external loads increase to $7.74 \mathrm{kN}$, as indicated by the second blue circle from origin in Fig. 14b), the outmost fibers at the mid-span of Member CX2 yield, and the maximum stress in the longitudinal direction and the von Mises stress are 250.01MPa and 250.01MPa, respectively. As the external load reaches $8.80 \mathrm{kN}$, the structure reaches its loading capacity. After Member CX2 and other members around the center buckle, the external load can still be increased from $2.16 \mathrm{kN}$ to $8.80 \mathrm{kN}$, which suggests that the structure can still resist the increasing external load after some members buckle. The load-displacement curve in this figure also shows that the buckling of Member CX2 is limit-load instability.

Figure 14a) presents the displacements at mid-spans of the same representative members in the $y$ direction. Associated with each load substep, the displacements and the deviation between displacements on all types of members are both very small, and no obvious softening behavior is observed. This verifies that the member buckles about the y axis.

\subsubsection{Validation of the Proposed Approach to Detect Buckling}

Figures 15-17 present the strain time histories of three representative members. Each figure presents the strain time histories at two cross sections of each member, Section A and Section B (refer to Fig. 2 for locations of A and B). The strains here are assumed to be the strains measured by strain gauges, which are actually the strains due to Load Substep 2. Appreciable deviation in strain is only observed in the buckled member (Fig. 15), validating the efficacy of the proposed approach. As shown in Fig. 15, buckling occurs at the first blue circle in the graph, where the 
strains at A and B start to significantly deviate from each other. The second blue circle from origin indicates the load substep at which the bending stress has been large enough to cause the material at Section A (mid-span) to yield.

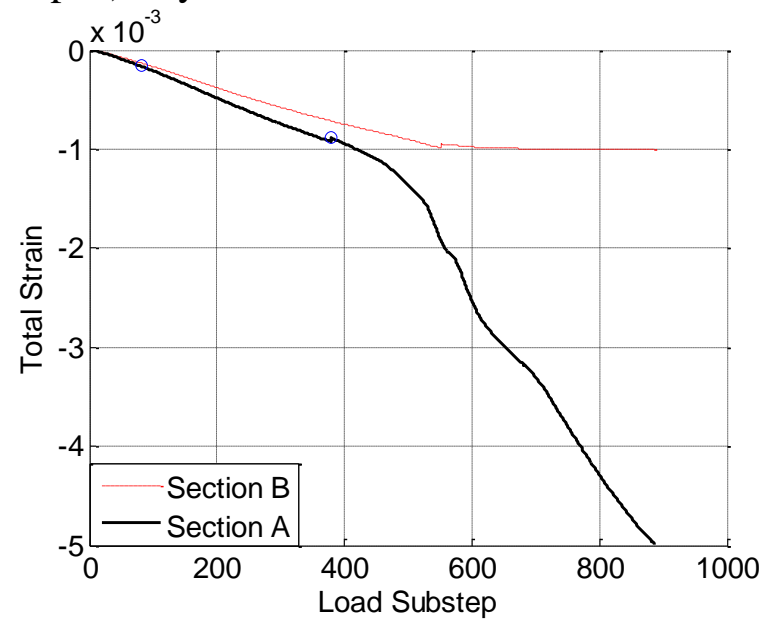

Fig. 15 Strain time history of a potentially buckled compression member

(Member CX2) in Model 2

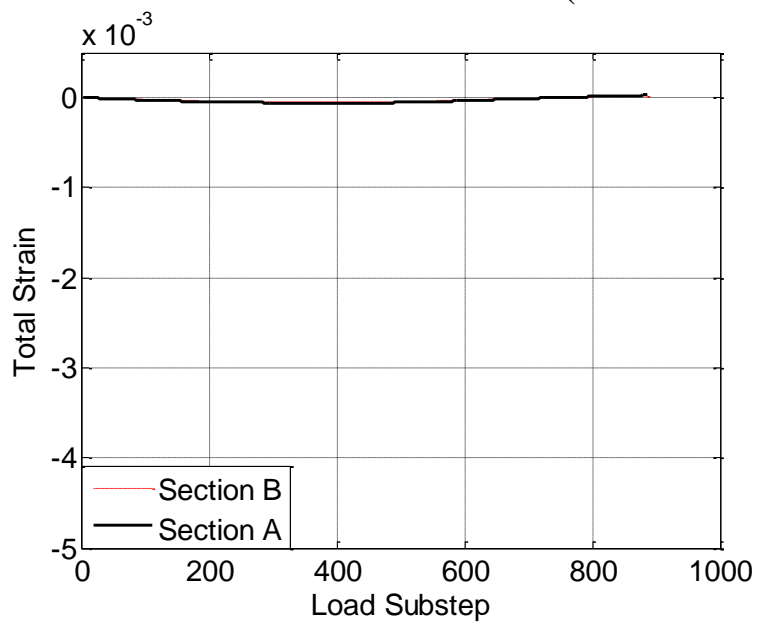

Fig. 16 Strain time histories of an unbuckled compression member (Member CX1) in Model 2

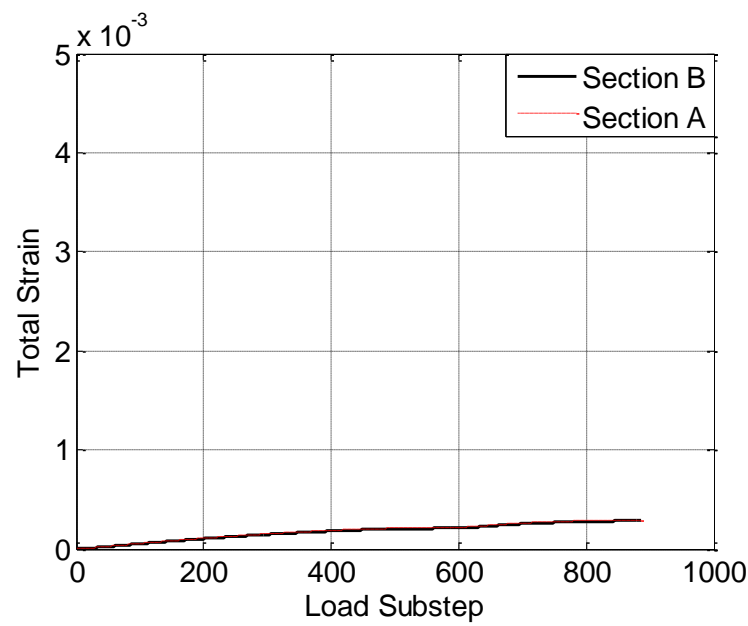

Fig. 17 Strain time histories of of a tension member (Member TX1) in Model 2

\subsection{Model 3: Members are rigidly connected and both self-weight gravity load and external loads are considered}

In this model, both ends of members are assumed fixed. The loading condition in this model is the same as in Model 2. Therefore, the simulation of losing stability used for Model 2 applies here. In this case study, it is observed that the members around the center of the upper layer buckle in the plane of the upper layer, about the $z$ axis.

\subsubsection{Classify the type of buckling}

Again the most critical loaded members are located around the center of the upper layer. From [1], for members with both ends fixed, $K=0.76$ (in-plane chord buckling). By substituting $K=0.76$, 
$E=2.0 \times 10^{11} \mathrm{~Pa}, L=8 \mathrm{~m}$ and $r=\sqrt{\frac{I}{A}}$ into Eq. (11), $F_{c r}$ is obtained as $78.99 \mathrm{MPa}$, which is less than the proportional limit stress of A36 steel (215 MPa). Therefore, the buckling in this model is classified as elastic buckling.

\subsubsection{Eigenvalue buckling analysis results}

Through an eigenvalue buckling analysis, the first eigenvalue (the critical buckling load) is obtained as $13.50 \mathrm{kN}$, which is much greater than that of Model 2 due to the fixed connections between members. The first buckling mode shape is presented in Fig. 18. It shows that the members around the center of the upper layer buckle in the plane of the upper layer.

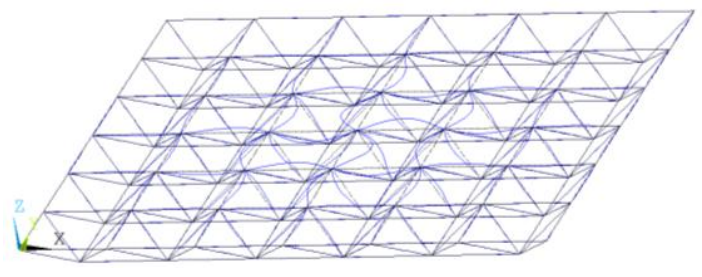

a) 3-D view

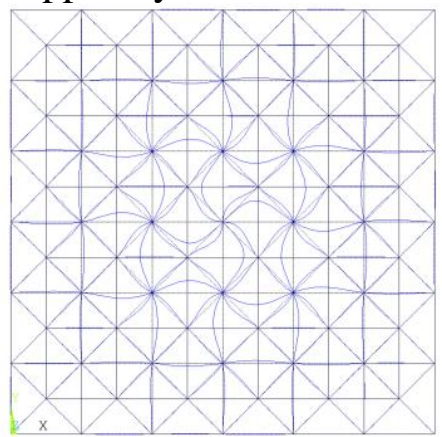

b) Plan view

Fig. 18 First buckling mode shape of Model 2

\subsubsection{Nonlinear buckling analysis based on the arc-length method}

Same as in Model 2, only the responses with the deduction of the responses due to Load Step 1 are presented in the following. This is to simulate that only the responses after the strain gauges are deployed are measured.

\subsubsection{Load-displacement curves}

Figure 19 presents the load-displacement curves of the nodes in the middle of four representative members, a potentially buckled compression member (Member CX3), an unbuckled compression member (Member CX1) and two tension members (Members TX3 and TX4). Figure 19a) presents the displacements in the $y$ direction. At the beginning of loading, the displacements of all four members approximately linearly increase with the external load, which suggests that the structure works in the elastic regime and no buckling has initiated yet. When the external load reaches $9.53 \mathrm{kN}$, as indicated by the first blue circle from origin, the displacement at the mid-span of Member CX3 starts to become nonlinear and an obvious softening behavior is observed on the graph for Member CX3; in addition, the displacement on Member CX3 starts to become more significant than those on the other three members. The above two observations indicate the onset of buckling of Member CX3. The magnitude of the maximum normal stress associated with the load of $9.53 \mathrm{kN}$ is $111.97 \mathrm{MPa}$, which is much smaller than the proportional limit stress. It verifies that Member CX3 experiences elastic buckling.

The stress results show that, as the external loads increase to $15.18 \mathrm{kN}$ (the second blue circle from origin in Fig. 19a), the outmost fibers at the mid-span of Member CX3 yield, and the 
maximum normal stress in the longitudinal direction and the von Mises stress reach $-250.17 \mathrm{MPa}$ and $250.17 \mathrm{MPa}$. As the external load increases to $20.43 \mathrm{kN}$, the structure reaches its loading capacity. After Member CX3 and other members around the center of the upper layer buckle, the external load can still be increased from $9.53 \mathrm{kN}$ to $20.43 \mathrm{kN}$. This figure also shows that the buckling of Member CX3 is limit-load buckling.

Figure 19b) presents the displacements at mid-spans of the same four representative members in the $z$ direction. Associated with each load level, the deviation between displacements on all types of members is not significant, and the difference in the softening behavior is not significant either. It verifies that the member buckles in the plane of the upper layer about the $z$ axis.

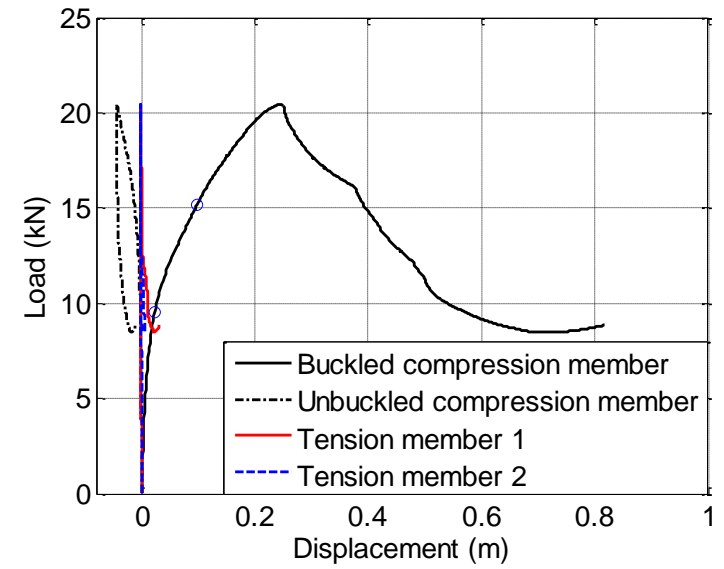

a) Displacement at midspan in the y direction

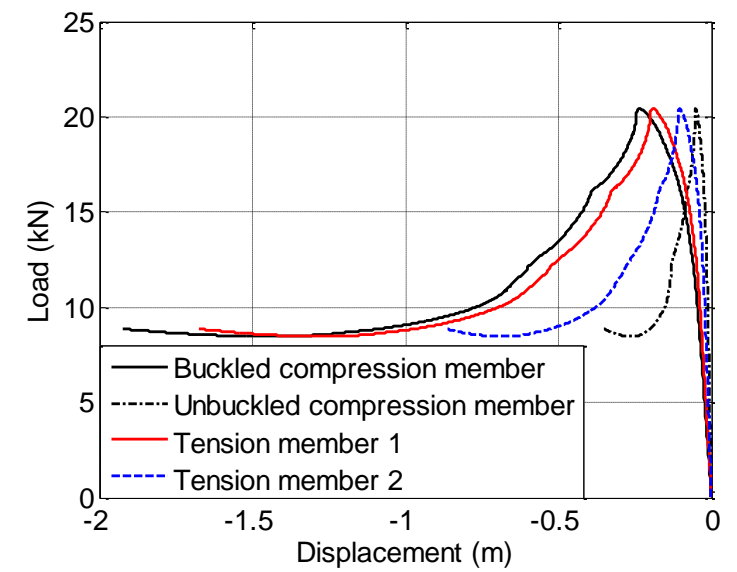

b) Displacement at midspan in the $\mathrm{z}$ direction

Fig. 19 Load-displacement curves for Model 3

\subsubsection{Validation of the Proposed Approach to Detect Buckling}

The strain deviations on three representative members (Members CX3, CX1 and TX3) between Sections A and B are presented in Figs. 20-22. From Fig. 20, at the beginning of loading, the strains at the two cross sections of the member are very close to each other, as the member is working in the elastic regime and no buckling happens yet. As the magnitude of external loads increases, the strains at the two sections start to deviate from each other, as indicated by the first blue circle, indicating that the load reaches the critical buckling load and the member buckling initiates. The second blue circle indicates the load substep at which the material at Section A starts to yield. The above verifies that buckling causes the deviation in normal strain along the member.

From Fig. 21, all the strains at the two sections are very small and remain the same or at the same order of magnitude as time evolves. Actually, although this member is in compression, the stress is too small to cause this member to buckle. From Fig. 22, although bigger strains are observed, all the strains at the two cross sections remain either the same or at the same order of magnitude as time evolves, indicating that this member does not suffer from buckling. Actually, this member is in the lower layer and only carries tensile forces. All the above results again validate that the deviation in measured normal strain along the member can be used to determine whether a member buckles or not. 


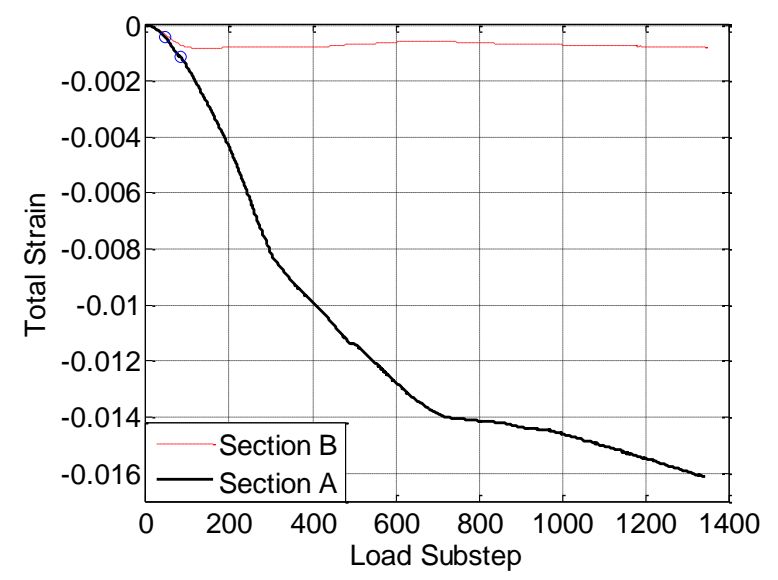

Fig. 20 Strain time history of a potenially buckled compression member (Member CX3) in

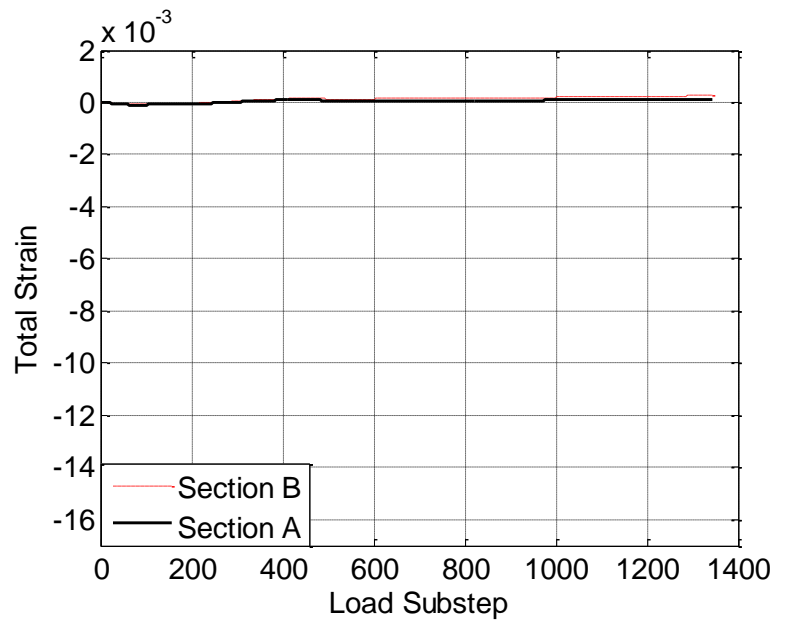

Fig. 21 Strain time histories of an unbuckled compression member (Member CX1) in Model 3

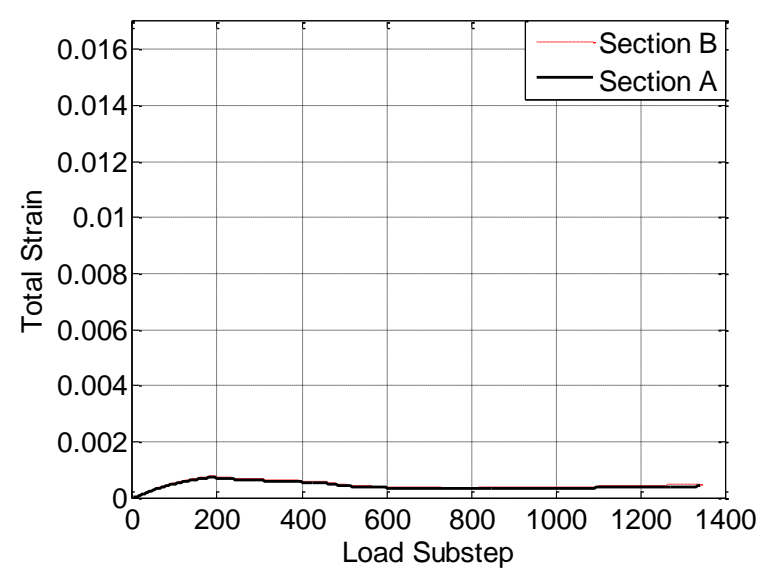

Fig. 22 Strain time histories of of a tension member (Member TX3) in Model 3

\section{Conclusions}

In this study, a novel approach to detect member overall buckling of civil space grid structures is proposed. This approach is based on the fact that the bending stress induced by buckling leads the normal strain on the surface of the member to vary significantly along the member, which can be reflected from the deviation in measured strains between two sections of the member. To validate the proposed research, a large-scale space grid structure was considered. Three finite element models of this structure are developed to consider different connections between members (pin-connected or rigidly connected) and loading situations. For each model, nonlinear buckling analysis is conducted to simulate the development of buckling in the structure. Three types of results are provided. The first type is the load-displacement curves, which are to show how buckling is developed; the second type is the axial stress/strain and bending stress/strain time histories, which are to verify that buckling introduces a large bending stress and the load-carrying characteristics of a potentially buckled member change due to buckling; and the third type is the time histories of the total normal strains on the surface of members. Only the third type of results is required when applying this approach to detect member overall buckling. 
The obtained results demonstrate that: 1) once a member buckles, the normal strain on the surface of this member significantly deviates from each other between cross sections, increasing from one end of the member to its center. No strain deviation is observed in unbuckled compression members or tension members; and 2) strain gauges can pick up all the bending stress induced by buckling as long as they are deployed before buckling.

The implementation of this approach can timely detect buckling of individual members, preventing buckling in a local area from expanding into an overall structural failure. This approach also provides the structural stability research community with a simple approach to detect whether a member buckles or not without the tedious effort of obtaining the loaddisplacement curves.

One advantage of the proposed approach is that the requirement on the measurement accuracy of strain gauges is very low. This is because this approach detects member buckling by looking for the deviation in the strains measured at two different cross sections in one member. The obtained results have shown that once a member buckles, the difference between the two measured strains on one member is very large (the two strain readings are not at the same magnitude order). Therefore, in practical applications, as long as the strain gauges with the same type and measurement accuracy are deployed, the proposed approach will work well.

The proposed approach has successfully detected buckling of members in space grid structures made of aluminum. It can also be applied to space grid structures made of other types of metal materials, such as steel. Although this approach is validated on a square-on-square staggered double-layer space grid structure, it can be applied to detect member buckling in space grid structures with other types of configurations.

This approach requires the strains to be measured at two cross sections in a member of interest for several time instants. Considering that how a member buckles is not known in advance, two strain gauges may be needed to be deployed at each cross section, one on the top or bottom surface and the other on one of the two side surfaces, to capture the surface strain of a member. This approach also requires that strain gauges be deployed before buckling occurs.

The effectiveness of the proposed approach will be further investigated by experimental tests on a space grid structure in the lab. Further research will be conducted to investigate whether this approach can be applied to detect inelastic buckling.

\section{Acknowledgements}

This work was supported by National Science Foundation, the Hazard Mitigation and Structural Engineering program, through the project of "Damage and Instability Detection of Civil Large-scale Space Structures under Operational and Multi-hazard Environments" [Award No.: 1455709].

\section{References}

[1] Cuoco DA. Guidelines for the design of double-layer grids. ASCE Publications 1997.

[2] Bazant ZP, Cedolin L, Chen WF, Lui EM. Stability of Structures: Elastic, Inelastic, Fracture and Damage Theories. J Struct Eng 1993;119(3):1001-2. 
[3] Ishikawa K, Okubo S, Hiyama Y, Kato S. Evaluation method for predicting dynamic collapse of double layer latticed space truss structures due to earthquake motion. Int J Space Struct 2000;15(3):249-57.

[4] Makowski ZS. New Trends in Spatial Structures. Department of Civil Engineering, University of Queensland 1986.

[5] Singer J. Recent studies on the correlation between vibration and buckling of stiffened cylindrical shells. Zeitschrift für Flugwissenschaften und Weltraumforschung 1979;3:33343.

[6] Singer J, Prucz J. Influence of initial geometrical imperfections on vibrations of axially compressed stiffened cylindrical shells. J Sound Vibration 1982;80(1):117-43.

[7] Qu W, Song W, Xia Y, Xu Y, Qin W, Jiang Z. Two-step method for instability damage detection in tower body of transmission structures. Adv Struct Eng 2013;16(1):219-32.

[8] Ravet F, Zou L, Bao X, Chen L, Huang RF, Khoo HA. Detection of buckling in steel pipeline and column by the distributed Brillouin sensor. Opt Fiber Tech 2006;12(4):305-11.

[9] Zhang C, Bao X, Ozkan IF, Mohareb M, Ravet F, Du M, DiGiovanni D. Prediction of the pipe buckling by using broadening factor with distributed Brillouin fiber sensors. Opt Fiber Tech 2008;14(2):109-13.

[10] Feng X, Wu W, Li X, Zhang X, Zhou J. Experimental investigations on detecting lateral buckling for subsea pipelines with distributed fiber optic sensors. Smart Struct Sys 2015;2(15):245-58.

[11] Feng X, Zhou J, Sun C, Zhang X, Ansari F. Theoretical and experimental investigations into crack detection with BOTDR-distributed fiber optic sensors. J Eng Mech 2013;139(12):1797-807.

[12] Feng X, Zhang X, Sun C, Motamedi M, Ansari F. Stationary wavelet transform method for distributed detection of damage by fiber-optic sensors. J Eng Mech 2013;140(4):04013004.

[13] Ryu CY, Lee JR, Kim CG, Hong CS. Buckling behavior monitoring of a composite wing box using multiplexed and multi-channeled built-in fiber Bragg grating strain sensors. NDT \& E Int 2008;41(7):534-43.

[14] Park JW, Ryu CY, Kang HK, Hong CS. Detection of buckling and crack growth in the delaminated composites using fiber optic sensor. J Compos Mater 2000;34(19):1602-23.

[15] Foraboschi P. Modeling of Collapse Mechanisms of Thin Reinforced Concrete Shells. J Struct Eng 1995;121(1):15-27.

[16] Foraboschi P. Experimental characterization of non-linear behavior of monolithic glass. Int J Nonlinear Mech 2014;67:352-70.

[17] Foraboschi, P. Laminated glass columns. Struct Eng 2009;87(18), 20-26.

[18] Foraboschi P. Buckling of a laminated glass column under test. Struct Eng 2009;87(1):2-8.

[19] Feng RQ, Ye J, Yao B. Evaluation of the buckling load of an elliptic paraboloid cablebraced grid shell using the continuum analogy. J Eng Mech 2012;138(12):1468-78.

[20] Feng RQ, Yao B, Ye J. Stability of lamella cylinder cable-braced grid shells. J Constr Steel Res 2013;88:220-30.

[21] Cai J, Gu L, Xu Y, Feng J, Zhang J. Nonlinear stability analysis of hybrid grid shells. Int J Struct Stab and Dyn 2013;13(01):1350006..

[22] Cai J, Zhou Y, Xu Y, Feng J. Non-linear stability analysis of a hybrid barrel vault roof. Steel Comp Struct 2013;14(6):571-86. 
[23] Cai J, Feng J, Xu Y, Wang K. Investigation of the Static and Dynamic Behavior of a Deployable Hybrid Grid Shell. Adv Struct Eng 2013;16(6):1103-11.

[24] Cai J, Zhou Y, Xu Y, Feng J. Non-linear stability analysis of a hybrid barrel vault roof. Steel Comp Struct 2013;14(6):571-86.

[25]Cai J, Xu Y, Wang F, Feng J, Zhang J. A computational study of the static and dynamic response of a hybrid barrel vault structure. Adv Steel Constr 2012;8(4):317-30.

[26] Shen ZY, Li YQ, Luo YF. Stability of single-layer reticulated shells. Int J Steel Struct 2004;4(4):289-300.

[27] Edition, A. F., \& Manual, S. C. American institute of steel construction. United States of America 2010;16.1-22.

[28] Edition, A. F., \& Manual, S. C. American institute of steel construction. United States of America 2010;16.1-33.

[29] Madi UR, El-Tayem AA. On the effective length of compression members in double-layer grids. Int J Space Struct 1991;6(1):33-9.

[30] Kurukuri S. Stability and geometrical nonlinear analysis of shallow shell structures. Bauhaus Universität, Weimar, Germany: Advanced Machanics of Materials and Structures Graduate School of Structural Engineering; 2004.

[31] ANSYS help. Section 7.5.2 Obtain the static Solution. ANSYS Version 15. 